\title{
Proteomics of red and white petals in petunia reveals a novel function of the anthocyanin regulator ANTHOCYANIN1 in determining flower longevity
}

Bhakti Prinsi $^{\mathrm{a}^{*}}$, Alfredo S. Negri ${ }^{\mathrm{a}}$, Francesca M. Quattrocchio ${ }^{\mathrm{b}}$, Ronald E. Koes ${ }^{\mathrm{b}}$, Luca Espen ${ }^{\mathrm{a}}$

${ }^{a}$ Dipartimento di Scienze Agrarie e Ambientali, Produzione, Territorio, Agroenergia (DISAA), Università degli Studi di Milano, via Celoria 2, 20133, Milano, Italia

${ }^{\mathrm{b}}$ Graduate School of Experimental Plant Sciences, Swammerdam Institute of Life Sciences, University of Amsterdam, Sciencepark 904, 1098 XH Amsterdam, The Netherlands

\section{Biological significance}

The pathway synthesizing anthocyanin pigments is highly conserved in the plant kingdom and is activated by a trio of transcription factors that are interchangeable even between distantly related monocot and dicot species. Here we show that ANTHOCYANIN1 (AN1), the bHLH transcription factor of this group, has in petunia a role in multiple processes. The proteomic and biochemical analyses of wild type (ANI) and mutant (anl) corolla limbs added interesting details to our knowledge of the transcriptional and post-transcriptional mechanisms regulating the flavonoid pathway. Moreover, the study revealed that the anl mutation has pleiotropic effects on floral longevity suggesting an unexpected role for AN1 and, at the same time, providing new insights on flower senescence at proteomic and physiological level. The results we discuss here open a novel view of the relation between flavonoid synthesis, vacuolar acidification and hormonal balance in flowers. 

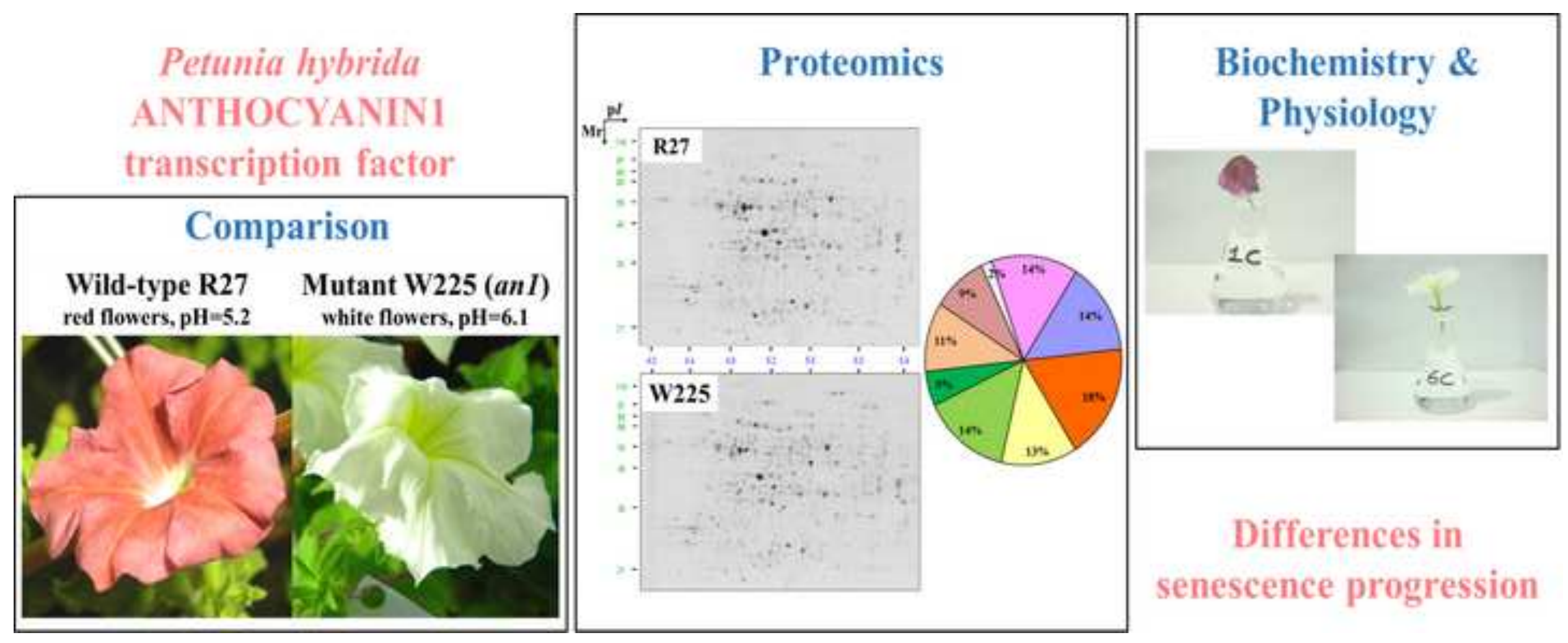


\section{Highlights}

- The anthocyanin regulator AN1 of petunia controls pigmentation unrelated processes

- Proteomics shows changes in anl flowers not anticipated by transcription regulation

- Proteomics indicates that the anl mutation induces a delay in flower senescence

- Flowers of anl mutants display prolonged longevity compared to wild type flowers

- anl cut flowers are insensitive to sugar feeding 
1 Proteomics of red and white corolla limbs in petunia reveals a novel function of the

2 anthocyanin regulator ANTHOCYANIN1 in determining flower longevity

3

$4 \quad$ Bhakti Prinsi $^{\mathrm{a}^{*}}$, Alfredo S. Negri $^{\mathrm{a}}$, Francesca M. Quattrocchio ${ }^{\mathrm{b}}$, Ronald E. Koes ${ }^{\mathrm{b}}$, Luca Espen $^{\mathrm{a}}$ 5

$6{ }^{a}$ Dipartimento di Scienze Agrarie e Ambientali, Produzione, Territorio, Agroenergia (DISAA),

7 Università degli Studi di Milano, via Celoria 2, 20133, Milano, Italia

$8{ }^{\mathrm{b}}$ Graduate School of Experimental Plant Sciences, Swammerdam Institute of Life Sciences,

9 University of Amsterdam, Sciencepark 904, 1098 XH Amsterdam, The Netherlands

11 *Corresponding author:

12 Bhakti Prinsi,

13 Dipartimento di Scienze Agrarie e Ambientali, Produzione, Territorio, Agroenergia (DISAA),

14 Università degli Studi di Milano, via Celoria 2, 20133, Milano, Italia

15 Tel: ++390250316610

16 E-mail address: bhakti.prinsi@unimi.it

17 
The Petunia hybrida ANTHOCYANIN1 (AN1) gene encodes a transcription factor that regulates both the expression of genes involved in anthocyanin synthesis and the acidification of the vacuolar lumen in corolla epidermal cells. In this work, the comparison between the red flowers of the R27 line with the white flowers of the isogenic an1 mutant line W225 showed that the AN1 gene has further pleiotropic effects on flavonoid biosynthesis as well as on distant physiological traits. The proteomic profiling showed that the anl mutation was associated to changes in accumulation of several proteins, affecting both anthocyanin synthesis and primary metabolism. The flavonoid composition study confirmed that the anl mutation provoked a broad attenuation of the entire flavonoid pathway, probably by indirect biochemical events. Moreover, proteomic changes and variation of biochemical parameters revealed that the anl mutation induced a delay in the onset of flower senescence in W225, as supported by the enhanced longevity of the W225 flowers in planta and the loss of sensitivity of cut flowers to sugar. This study suggests that AN1 is possibly involved in the perception and/or transduction of ethylene signal during flower senescence. hormonal balance in flowers. 


\section{Introduction}

Flavonoids are a broad class of phenylpropanoids, characterized by a C6-C3-C6 skeleton with a phenylbenzopyran moiety, embracing several subgroups, such as flavanones, flavones, flavonols and anthocyanins [1]. In plants, flavonoids are involved in several biological processes, like protection against (a)biotic stresses, male fertility, auxin transport and pigmentation of different organs [2,3]. Among flavonoids, anthocyanins are the major pigments in flowers and fruits. In the last decades, petunia (Petunia hybrida) was extensively used as a model species in plant biology [4] and, in particular, to elucidate biochemical and molecular aspects underlying flower pigmentation.

In petunia flowers, anthocyanins accumulated in the epidermal cells impart colours ranging from red to purple [5,6]. The anthocyanin biosynthesis involves about 10-15 structural genes [7] classified in two groups subjected to distinct controls: the Early Biosynthetic Genes (EBG), encoding enzymes of the first biosynthetic steps, and the Late Biosynthetic Genes (LBG), that, starting from dihydroflavonol 4-reductase (DFR), encode for the enzymes specific for anthocyanin synthesis and decoration [8]. Anthocyanins are synthetized in the cytoplasm and then accumulated in the central vacuole by transport systems mediated by a glutathione $S$ transferase-like protein, encoded by the AN9 locus, acting as ligandin to deliver anthocyanins to tonoplast $[9,10]$. The colour spectrum of anthocyanins depends on chemical modifications, on the presence of metal ions and co-pigments as well as on the $\mathrm{pH}$ of the vacuolar lumen $[5,11,12]$. Studies in petunia, snapdragon (Antirrhinums genus) and Arabidopsis thaliana provided the main information about transcriptional regulation of anthocyanin accumulation in dicots. This regulatory machinery involves a transcription factor complex (WMB complex) consisting of a WD40 protein, a basic Helix-Loop-Helix (bHLH) and a R2R3 MYB protein that activate transcription of the structural genes. The bHLH and MYB proteins determine the spatial and temporal expression of structural anthocyanin genes, and thereby the distinct pigmentation patterns of different species $[13,14]$. Interestingly, this regulatory machinery is also involved in the control of other processes related to cell morphogenesis, both in reproductive and in vegetative organs (for review see [5,15]). The transcription factor ANTHOCYANIN1 (AN1) of petunia provides a good example of the multiplicity of mechanisms regulated by the proteins

77 participating to the WMB complex. AN1 is a bHLH protein mainly expressed in flower corolla 
the MYB proteins AN2, activating the expression of LBG [16] in the corolla. By a distinct mechanism involving the MYB protein $\mathrm{PH} 4$, AN1 promotes the hyper-acidification of the vacuolar lumen in corolla epidermal cells just before the bud opening $[11,12,18,19]$. Interestingly, the phenotype of anl mutants shows that $A N 1$ also promotes anthocyanin stability in corolla and inhibits cell division in the seed coat $[18,19]$. Proteomics provides useful tools to analyse biochemical relations among different metabolic and physiological processes. This approach was successfully exploited to examine novel aspects of fruit and flower development. In grapevine (Vitis vinifera) changes in the proteome of grape skin during ripening revealed links between anthocyanin accumulation and the glycolytic pathway [20]. Likewise, proteomic analysis in rose (Rosa hybrida) highlighted that petal maturation and flower opening imply stage-specific regulation of energy metabolism, cell-rescue and stress responses [21] and the proteomic analysis of petunia corolla after pollination identified novel proteins engaged in corolla senescence [22].

In order to study in detail the multiple metabolic roles of AN1, we compared open flowers from the petunia red flowering line R27 with those from the isogenic white flowering anl W225 mutant [18]. The integration of proteomic and chemical analyses highlighted novel effects of the an1 mutation on the flavonoid pathway in W225. Moreover, the an1 mutation was related to a broad spectrum of proteomic changes, mostly associable to a delay in the onset of corolla limb senescence. The biochemical and physiological evaluations confirmed that the W225 line was characterized by a prolonged flower longevity in planta and by a loss of sensitivity of cut flowers to sugar feeding, suggesting the involvement of AN1 in the perception of ethylene signals.

\section{Materials and methods}

\subsection{Plant material}

The petunia (Petunia hybrida) line R27 has functional alleles for all the regulatory genes that control anthocyanin accumulation and colour in corollas but contains mutation in the genes HYDROXYLATION AT FIVE 1 and 2 and RHAMNOSYLATION AT THREE, encoding for flavonoid 3'5' hydroxylase [23] and anthocyanin rhamnosyl transferase (RT; [24]), respectively. In addition, $\mathrm{R} 27$ harbours a recessive allele of the $F L$ locus $[25,26]$ which diminishes the flavonol synthesis and increases the accumulation of cyanidin derivatives. Hence, R27 has bright red coloured flowers because the major anthocyanins produced are cyanidin derivatives ([27]; 
Fig. 1). Insertion of a $d T P H 1$ transposon in an intron/exon boundary of the AN1 gene created a genetically unstable an1 mutant (W138) in the R27 background [16]. Germinal excision of this dTPH1 element created a stable recessive null anl allele $\left(a n 1^{\mathrm{W} 225}\right)$ in which a footprint disrupts the splice site. As consequence of this mutation, the W225 line has white flowers and increased vacuolar $\mathrm{pH}$ in corolla cells ([18]; Fig. 1).

Plants were grown in pots in a growth chamber under a photoperiod of $16 \mathrm{~h}: 8 \mathrm{~h}$ light : dark with a temperature of $20^{\circ} \mathrm{C}$ in the dark and $24^{\circ} \mathrm{C}$ in the light and a relative humidity of $65 \%$. In order to obtain homogeneous samples, only corolla limbs were collected from flowers at 1 day after anthesis (DAA). Each independent biological sample consisted of the corolla limbs of 10 flowers, picked from at least five plants. Each sample was immediately frozen in liquid nitrogen and conserved at $-80^{\circ} \mathrm{C}$ until further use.

\subsection{2-DE analysis}

The proteomic comparison between wild type (WT; R27) and anl (W225) flowers was performed according to the procedures described previously [28] with the following refinements. The proteins were extracted from frozen samples finely powdered in liquid nitrogen, added with $5 \%$ of polyvinylpolypyrrolidone and directly suspended in 5 volumes of phenol. In order to extract the total protein fraction, an adequate aqueous buffer was adopted [0.7 $\mathrm{M}$ sucrose, $10 \mathrm{mM}$ $\mathrm{Na}_{2}$-EDTA, $4 \mathrm{mM}$ ascorbic acid, 0.2\% (v/v) Triton X-100, $1 \mathrm{mM} \mathrm{PMSF,} 0.1 \mathrm{mg} \mathrm{ml}^{-1}$ Pefabloc, $0.4 \%(\mathrm{v} / \mathrm{v}) \beta$-mercaptoethanol]. The final pellet was suspended in an IEF buffer [7 $\mathrm{M}$ urea, $2 \mathrm{M}$ thiourea, 3\% (w/v) CHAPS, 1\% (v/v) NP-40, $50 \mathrm{mg} \mathrm{ml}^{-1}$ DTT and 2\% (v/v) IPG Buffer pH 4-7 (GE Healthcare Life Sciences)] compatible with the following electrophoretic analyses, conducted in a 4-7 pH range on $10 \%$ polyacrylamide gels, loading on each gel $400 \mu \mathrm{g}$ of proteins. Three independent biological replicates were extracted for each flower line $(n=3)$. Two technical replicates were produced for each protein sample, thus obtaining six gels for each flower line. The 2-DE were stained with colloidal Coomassie Brilliant Blue G-250 (cCBB) and analysed as previously described [28]. Relative spot volumes $(\% \mathrm{Vol})$ were normalized $\left[\mathrm{x}=\log _{2}\right.$ $(\%$ Vol+1)] and analysed according to the Student's t-test to select the significant changes ( $\mathrm{p}<0.001)$. Only spots showing at least a 2-fold threshold in $(\% \mathrm{Vol})$ change between the R27 and W225 proteomes were considered for the successive analyses. The \% Vol of the selected spots were further analysed by the nested ANOVA test to verify that the technical variability was 
negligible respect than the difference between the two lines. The Fig. S2 reports the Volcano plot showing the distribution of the spot variations derived from the comparison of R27 and W225 lines.

\subsection{Protein identification by nLC-nESI-MS/MS}

The spots of interested were excised from preparative gels loaded with $400 \mu \mathrm{g}$ of proteins and stained with the cCBB procedure. After trypsin digestion [28], each single spot was analysed by an Agilent 6520 Q-TOF mass spectrometer equipped with an HPLC Chip Cube source driven by a 1200 series nano/capillary LC system (Agilent Technologies). The nLC separation was done on $75 \mu \mathrm{m}$ x 43-mm column (Zorbax SB, C18, 300 Å), applying a 13-min acetonitrile (ACN) gradient (from $5 \%$ to $60 \% \mathrm{v} / \mathrm{v}$ ) in $0.1 \%(\mathrm{v} / \mathrm{v})$ formic acid (FA) at $0.4 \mu 1 \mathrm{~min}^{-1}$. The mass spectrometer ran in positive ion mode acquiring $4 \mathrm{MS}$ spectra s${ }^{-1}$ from 300 to $3000 \mathrm{~m} / \mathrm{z}$. The auto-MS/MS mode was applied from 50 to $3000 \mathrm{~m} / \mathrm{z}$ with a maximum of 4 precursors per cycle and an active exclusion of 2 spectra for $0.1 \mathrm{~min}$. Peptide identification was performed by protein database searching with Spectrum Mill MS Proteomics Workbench (Rev A.03.03; Agilent Technologies). Search parameters were precursor match tolerance $\pm 20 \mathrm{ppm}$ and product mass tolerance $\pm 40 \mathrm{ppm}$. Cysteine carbamidomethylation and methionine oxidation were set as fixed and variable modifications, respectively, accepting two missed cleavages per peptide. The search was done against the subset of Petunia spp. protein sequences (1189 entries) or against the subset of Viridiplantae protein sequences (1733282 entries), downloaded from the National Center for Biotechnology Information (http://www.ncbi.nlm.nih.gov/). Both databases were concatenated with the respective reverse one. The threshold used for peptide identification was Spectrum Mill score $\geq 9, \mathrm{SPI} \% \geq 50 \%$ and accepting only peptides with the difference between forward and reverse scores $\geq 2$, in order to remove the incidence of false positive hits. Finally, the peptide assignments were manually checked to select the best hit among possible peptide variants due to redundancy or single amino acid substitutions. If not assigned in Petunia database, each single spot was individually characterized by search against the Viridiplantae database. When the peptides were identified on different homologous, in order to individuate the protein sequence that better embraces all the peptides a protein similarity search was performed by the FASTS algorithm [29] (http://fasta.bioch.virginia.edu/fasta_www2). The homologous accession numbers and the statistical evaluation of the FASTS procedure are reported in the 
172 supplementary Table S1. Physical properties of the characterized proteins were predicted by in

173 silico tools at ExPASy (http://web.expasy.org/compute_pi/).

174

175

176

177

178

179

180

181

182

183

184

185

186

187

188

189

190

191

192

193

194

195

196

197

198

199

200

201

202

\subsection{Analysis of flavonoid compositions in corolla limbs}

The R27 and W225 frozen samples were finely powdered by pestle and mortar in liquid nitrogen and suspended in 3 volumes of $90 \%(\mathrm{v} / \mathrm{v})$ methanol and $0.1 \%(\mathrm{v} / \mathrm{v}) \mathrm{FA}$. After gentle sonication $\left(10 \mathrm{~min}\right.$ at $4^{\circ} \mathrm{C}$ ), the samples were centrifuged at $5,000 \mathrm{~g}$ at $4^{\circ} \mathrm{C}$ for $20 \mathrm{~min}$. The supernatants were filtered onto a sterilized PVDF hydrophilic membrane with pores of $0.45 \mu \mathrm{m}$ (Millex-HV, Millipore). Three independent biological samples were analysed for each flower line $(n=3)$ by nLC-nESI-MS/MS using an Agilent 6520 Q-TOF mass spectrometer equipped with an HPLC Chip Cube source driven by a 1200 series nano/capillary LC system (Agilent Technologies). The nLC separation was done on $75 \mu \mathrm{m} \times$ 43-mm column (Zorbax SB, C18, $80 \AA$ A), applying a 25min ACN gradient (stationary at $1 \%$ until $1 \mathrm{~min}$, to $10 \%$ at $2 \mathrm{~min}$, to $20 \%$ at $20 \mathrm{~min}$ and to $40 \%$ at $25 \mathrm{~min}$ ) in $0.1 \%(\mathrm{v} / \mathrm{v}) \mathrm{FA}$ at $0.4 \mu 1 \mathrm{~min}^{-1}$. The ESI source voltage was adapted to the ACN percentage. The mass spectrometer ran in positive ion mode acquiring MS scans over a range from 125 to $1500 \mathrm{~m} / \mathrm{z}$ at 1 spectra s $^{-1}$ and MS/MS spectra in a range of 100 to $3000 \mathrm{~m} / \mathrm{z}$ with a collision energy of $10 \mathrm{~V}$. Chromatographic peaks interpretation was performed with the MassHunter Workstation Software (version B.03.01, Agilent Technologies). Compounds were identified as positive ions ( +1 charge state) with a tolerance of $\pm 5 \mathrm{ppm}$. The search was conducted against a database consisting of main molecules of the flavonoid pathways (maps from 00941 to 00944) of KEGG pathways website (http://www.genome.jp/kegg/pathway.html), added with the possible mono/di/tri methylated and glucosylated forms (632 entries).

Compounds quantification was performed using external calibration curves. The significance of the difference of each flavonoid class between R27 and W225 was assessed through Student's ttest $(n=3, p<0.05)$.

\subsection{Determination of biochemical parameters in corolla limbs}

Reducing sugar and sucrose contents in R27 and W225 frozen samples were measured by colorimetric method [30] as described previously [31]. To evaluate the glutathione content, frozen corolla limbs were finely powdered by pestle and mortar in presence of liquid nitrogen and suspended in 4 volumes of $1 \mathrm{~N} \mathrm{FA}$. After an incubation of 5 min at $4{ }^{\circ} \mathrm{C}$, the samples were 
centrifuged at $15,000 \mathrm{~g}$ at $4^{\circ} \mathrm{C}$ for $20 \mathrm{~min}$. The supernatants were collected and filtered onto a sterilized PVDF hydrophilic membrane with pores of $0.45 \mu \mathrm{m}$ (Millex-HV, Millipore). The samples were analysed by nLC-nESI-MS using an Agilent 6520 Q-TOF mass spectrometer equipped with an HPLC Chip Cube source driven by a 1200 series nano/capillary LC system (Agilent Technologies). The nLC separation was done on a $75 \mu \mathrm{m}$ x 43-mm column (Zorbax SB, $\mathrm{C} 18,80 \AA$ ) by $10 \mathrm{~min}$ of isocratic elution with $1 \%$ (v/v) ACN in $0.1 \% \mathrm{FA}$ at $0.5 \mu 1 \mathrm{~min}^{-1}$. The mass spectrometer ran in positive ion mode and the MS scans were acquired over a range from 150 to $700 \mathrm{~m} / \mathrm{z}$ at 1 spectra $\mathrm{s}^{-1}$. Chromatographic peaks were extracted for GSH (reduced glutathione; m/z: 309.8, $[\mathrm{M}+\mathrm{H}]^{+1}$ ) and GSSG (oxidized glutathione; m/z: $307.08[\mathrm{M}+2 \mathrm{H}]^{+2} ; \mathrm{m} / \mathrm{z}$ : $613.16[\mathrm{M}+\mathrm{H}]^{+1}$ ) with a tolerance of $\pm 20 \mathrm{ppm}$. Compound quantification was performed using external calibration curves. Total glutathione content was calculated according to the following formula: total glutathione $=\mathrm{GSH}+2 *$ GSSG. Six independent biological samples were analysed for each flower line $(n=6)$. The significance of the differences was assessed through Student's ttest $(\mathrm{p}<0.01)$.

\subsection{Evaluation of flower longevity}

Flower longevity was evaluated both in planta and in detached flowers. The flowers were harvested at 1 DAA, a small portion of pedicel was trimmed off with a razor-blade, and the flowers were placed on floating supports in flasks containing double-distilled water or $10 \mathrm{mM}$ sucrose. The solutions were refreshed every day. The longevity of flowers was measured in $\mathrm{h}$ after anthesis, examining the wilting status at $12 \mathrm{~h}$-intervals. The evaluations were conducted on six flowers from at least three plants, analysed in triplicate $(n=3)$. The significance of the differences was assessed through factorial ANOVA ( $\mathrm{p}<0.01$, Tuckey post hoc test).

\section{Results}

\subsection{Proteomic comparison of corolla limbs between $\mathrm{R} 27$ and $\mathrm{W} 225$}

The proteomic comparison of fully open flowers of the R27 and W225 lines was used to investigate whether AN1 controls other metabolic traits than anthocyanin biosynthesis in petunia flowers. R27 has bright red flowers in which the major pigments are cyanidin derivatives [27]. The W225 line contains an an1 null allele that resulted from the insertion and subsequent excision of a transposon in a splice site of the $A N 1$ gene in the R27 line. This transposon left 
behind a footprint that permanently inactivates the gene and results in white corolla with increased vacuolar pH ([16]; Fig. 1).

For the analysis of the total proteome, a phenol-based extraction was applied on frozen corolla limbs. This procedure resulted in a protein yield of $1.12 \pm 0.20 \mathrm{mg} \mathrm{g}^{-1} \mathrm{FW}$ from the red AN1 corolla limbs and $1.61 \pm 0.10 \mathrm{mg} \mathrm{g}^{-1} \mathrm{FW}$ from the white $a n l$ ones. The comparative proteomic analysis was performed in a $\mathrm{p} I$ range from 4 to 7 . These procedures, combined with cCBB, visualized an average of 1600 spots. The protein profiles showed a satisfactory degree of resolution (Fig. 1 and Fig. S1). The comparison between the AN1 and an1 maps revealed 62 spots that showed statistical significant differences in the accumulation levels and through a nested ANOVA procedure it was possible to appreciate the good reproducibility among the gels of the same condition, showing only negligible variations (data not shown). Fifty-eight of them were collected from preparative gels and sequenced by nLC-nESI-MS/MS. This approach allowed to characterize 56 spots (Table 1 and Table S1). Table 1 and Fig. 2 report the protein identification and quantification in the R27 and W225 proteomes and their electrophoretic positions. We grouped the proteins by metabolic function, according to their description in literature and GeneBank, pointing out nine main classes (Table 1 and Fig. 3). In detail, the identified proteins were involved in anthocyanin metabolism (14\%), carbon (14\%) and mitochondrial (18\%) metabolism, amino acid metabolism (13\%), endomembrane system (14\%), volatile biosynthesis $(5 \%)$, protein turnover $(11 \%)$, redox status $(9 \%)$, and hormone biosynthesis $(2 \%)$. All enzymes involved in the anthocyanin pathway were more abundant in the red flowers while white flowers were characterized by higher levels of enzymes related to primary cell functions such as carbon, energy, and amino acid metabolisms (Table 1).

\subsection{Proteins involved in anthocyanin metabolisms were still accumulated in 1 DAA} corolla limbs and were more abundant in the wild type than in the an1 line

The proteomic analysis of corolla limbs indicated that several enzymes involved in anthocyanin synthesis, decoration and transport were abundant in AN1 R27 flowers at 1 DAA (Table 1). In particular, we identified the chalcone flavone isomerase A (CHI) specifically expressed in corolla limbs and tube [32], a flavanone 3-hydroxylase (F3H; [33]), a DFR [34], three isoforms of anthocyanin 5-O-glucosyltransferase (5-GTa-c), the anthocyanin methyltransferase encoded by the $M F 2$ gene (AMT; [35]), and the glutathione S-transferase involved in anthocyanin 
compartmentation to the vacuole (AN9; [10]). Interestingly, the enzymes involved in the anthocyanin decorations, such as the three 5-GTs and the AMT were the most abundant proteins identified in R27 limbs, reaching 1.021 $\pm 0.047 \%$ Vol (summing the three spots) and 0.958 \pm 0.031 $\% \mathrm{Vol}$, respectively (Table 1). The amount of all these proteins was clearly lower in anl W225 flowers. Among the enzymes encoded by EBG, CHI diminished more than $75 \%$ and F3H showed a two-fold decrease in abundance in anl compared to AN1 flowers. Similarly, the enzymes encoded by LBG such as DFR, 5-GTa-c, AMT and AN9 were represented by only very faint spots in the proteomic pattern of anl corolla limbs.

\subsection{Flavonoid composition in $\mathbf{R} 27$ and $W 225$ corolla limbs}

The anthocyanins in R27 limbs mainly consisted of cyanidin-related compounds. In particular, cyanidin 3-O-glucoside accounted for c. $48 \%$ of the total anthocyanin content, its glycosides for a total of $39 \%$ and its methylated derivative, peonidin glucoside, for the remaining 13\% (Table 2). In addition to the lack of anthocyanins, W225 showed an increment of flavanones and dihydroflavonols (Table 2). Dihydroquercetin showed the highest increment $(+237 \%)$ in anl corolla limbs, where, together with its glucoside, it was the most abundant compound $(3.06 \pm 0.30$ $\left.\mu \mathrm{mol} \mathrm{g} \mathrm{g}^{-1} \mathrm{FW}\right)$. Also the content of flavanones was higher (+75\%) in anl flowers respect to the $A N 1$ ones, mainly due to a peculiar accumulation of eriodictyol glucoside to $0.45 \pm 0.02 \mu \mathrm{mol} \mathrm{g}{ }^{-}$

${ }^{1} \mathrm{FW}$, which was in line with our finding that the F3H enzyme was less abundant in W225 corolla limbs (Table 1). Otherwise, quercetin derivatives were less abundant in W225 corolla limbs, where only glucosylated forms were present. Altogether, the total concentration of flavonoids was more than $25 \%$ higher in R27 flowers $\left(7.72 \pm 0.80 \mu \mathrm{mol} \mathrm{g}{ }^{-1} \mathrm{FW}\right)$ than in an1 mutant W225 flowers $\left(5.61 \pm 0.39 \mu \mathrm{mol} \mathrm{g}^{-1} \mathrm{FW}\right)$.

\subsection{R27 and W225 corolla limbs differed in accumulation of proteins involved in carbon, energy and amino acid metabolism}

The analysis of the proteins showing differential accumulation in AN1 R27 and an1 W225 corolla limbs revealed an higher abundance of proteins involved in carbon metabolism in W225 flowers as compared to the R27 ones (Table 1), including some from the Calvin cycle, the pentose phosphate pathway and the glycolysis. Because of the high homology shared with chloroplastic chaperones involved in the assembly of RuBisCO oligomers, the heat shock protein 
60 (HSP60a) was included in this category (Table 1). A higher abundance in W225 corolla limbs was also detected for enzymes of the tricarboxylic acid cycle and two members of the photorespiration process, glycine dehydrogenase (GDH) and lipoamide dehydrogenase (LDH). Also the oxalate catabolic enzyme oxalyl-CoA decarboxylase (OXC) and the chaperonin CPN60 (HSP60b) were more abundant in W225 compared to R27 flowers (Table 1).

Similarly, the enzymes involved in the biosynthesis of pyridoxine (PDX), of serine (D-3phosphoglycerate dehydrogenase, (3PGDHa and b), of cysteine (cytosolic cysteine synthase 7, CysS) and in the S-adenosylmethionine cycle (methionine synthase, MS; S-adenosylmethionine synthase 3, MAT) showed higher levels in white flowers. Within this functional class, alanine aminotransferase (AlaAT) was the only enzyme that was more abundant in R27 than in W225 corolla limbs (Table 1).

\subsection{Several proteins participating to the endomembrane system were differentially} accumulated in red and white corolla limbs

Several proteins involved in the endomembrane system were among the ones showing differential abundance in ANI and anl corolla limbs (Table 1). A protein sharing high homology to the Gossypium hirsutum Reversibly Glycosylated Polypeptide like2 (RGP) was in this group. Homologs of RGP in arabidopsis and tobacco (Nicotiana tabacum) play a role in inhibiting intercellular transport via plasmodesmata [36] and, by our study, we showed that RGP was roughly three fold more abundant in R27 corolla limbs that in the W225 ones.

Likewise, a member of the SGNH superfamily of extracellular lipases was more abundant in R27 samples (SGNH). Proteins of this family are involved in the deposition of the cuticle layer, in epidermal cell differentiation and other steps of membrane recycling and membrane traffic [37]. Moreover, two members of the small GTPase family (Rab1 and Rab11) required for transport between ER and Golgi [38,39] were more abundant in R27 as well as a plasma membrane receptor kinase (RK).

A $22 \mathrm{kD}$ polypeptide (22P) belonging to the DREPP family (Developmentally Regulated Plasma Membrane Polypeptides), a NEM sensitive fusion protein (NSF, homohexameric AAA ATPases involved in membrane fusion) and the chloride intracellular channel (CLIC) were instead less abundant in R27 than in W225 corolla limbs. 


\subsection{Enzymes of the volatile biosynthetic pathway were affected by the an1 mutation} The R27 and W225 corolla limbs also diverged in the accumulation of three enzymes producing minor components of the volatile fragrance of petunia flowers (Table 1). Benzoyl-CoA:benzyl alcohol/phenylethanol benzoyltransferase (BPBT), required for the production of benzylbenzoate and phenylethylbenzoate, was present in double amount in W225 compared to R27, while two different forms of eugenol synthase (EGSa and b) showed opposite profiles between red and white corolla limbs (Table 1). These two forms were assigned to the same sequence (ABR24115) and, in both MS/MS analyses, the peptide containing amino acid residues determining product specificity (Q86 and L89, [40]) was sequenced (Table S1). Because R27 and derived lines (like W225) are not scented [40], the characterization of the effect of the two forms of the EGS enzyme will need to be assessed in a different genetic background.

\subsection{The an1 mutation also affected the accumulation of proteins involved in protein turnover, cell redox status and in the ethylene biosynthesis}

Another class of differentially abundant proteins was related to protein turnover. In particular, two distinct cysteine proteases (P21 and CP) were highly more abundant in AN1 R27 corolla limbs, while their inhibitor (CPI) was only detectable in the anl W225 ones. In addition, the proteasome $\alpha$ subunit (PS $\alpha$ ) and the glycyl-tRNA synthetase (GtRNAS) were more abundant in W225 than in R27, while the amount of oligopeptidase A (OPD) was instead lower (Table 1). Moreover, five proteins involved in the cell redox status were differentially abundant in R27 and W225 corolla limbs (Table 1). Interestingly, two forms of glutathione transferase (GSTa and b; not similar to AN9 which is directly involved in flavonoid metabolism) and two spots identified as monodeydroascorbate reductase (MDARa and b) were assigned to the same sequence (P46423 and Q43496, respectively), as reported in Table S1. Since the two members of each couple showed opposite trends of accumulation in the two lines, it is possible that this is associated with post-translational modifications (PTM). In particular, their reciprocal electrophoretic position suggested that such modification could be a phosphorylation.

Finally, our analysis showed that the 1-aminocyclopropane-1-carboxylate oxidase (ACO) was more abundant in R27 than in W225 (Table 1). ACO is an ethylene-forming enzyme which expression is up regulated during autocatalytic ethylene production at flower opening and wilting [41]. The FASTS analysis (Table S1) selected the protein of Orobanche minor (BAF33504; 
98.3\% identity) as best hit, but it also discriminated among the three isoforms in petunia, indicating the highest similarity (96.6\% of identity) with the corolla limb specific isoform ACO1 (Q08506; [41]). The other isoforms showed identity levels lower than 95\%. The dissimilarity between the sequenced peptides and the petunia Q08506 was limited to two amino acids (N154/T and D283/E), suggesting polymorphism between different lines of P. hybrida.

\subsection{Evaluation of senescence-related parameters, flower longevity in planta, and} responses to sucrose feeding in $\mathrm{R} 27$ and $\mathrm{W} 225$ cut flowers

In order to study at what phase of senescence the flowers were at the time of sampling, we evaluated several senescence-related parameters in flowers from the two lines. At 1 DAA, both the red and white flowers showed neither shape anomalies nor wilting symptoms (Fig. 1). The flowers of R27 and W225 were characterized, at this stage of development, by similar fresh weights and elevated water content (Table 3). In addition, the total glutathione concentration in the corolla limbs of both lines was about $34 \mathrm{nmol} \mathrm{g}^{-1} \mathrm{FW}$, with similar proportions between reduced and oxidized form (Table 3). The only significant differences regarded sugar metabolism. While the sucrose levels were comparable between R27 and W225 corolla limbs, the red ones had higher contents of reducing sugars (Table 3). Because this analysis did not detect osmotic and/or oxidative stress, it indicated that at 1 DAA R27 flowers were in the first phase of senescence. We compared flower longevity in R27 and W225 (Table 4; Fig. S3). The intact flowers on R27 plants showed wilting symptoms at $72.0 \pm 1.1 \mathrm{~h}$ after anthesis while the W225 flowers showed a life span of $123.3 \pm 2.9 \mathrm{~h}$, indicating that the anl mutation was associated with a prolonged longevity in undetached flowers. In addition, the mutation also affected the behaviour of cut flowers (Table 4; Fig. S3). The cut flowers from both lines showed shorter life span compared to flowers in planta when fed with water. The average life span of flowers dropped to $55.3 \pm 1.8 \mathrm{~h}$ for R27 and to $70.7 \pm 1.3 \mathrm{~h}$ for W225. However, while sucrose supply resulted beneficial to R27, restoring flower longevity similar to that showed in planta, on the contrary, in W225 flowers the supply of sugar did not alleviate the severe drop in longevity caused by detachment from the plant (Table 4).

\section{Discussion}


Recent findings in petunia and Arabidopsis indicate that the deeply conserved WMB complex controls besides anthocyanin synthesis several additional pathways involved in the terminal differentiation of epidermal cells, which, curiously, differ between species [15]. To uncover additional processes, including post-translationally controlled mechanisms, that are regulated by AN1 in petunia corolla we compared the proteomes of AN1 (R27) and an1 (W225) corolla limbs. The comparison of the 2-DE proteomic maps highlighted the proteins differentially accumulated between R27 and W225 flowers (Table 1, Figure 3), suggesting that the mutation in the AN1 gene had ample pleiotropic effects on flower metabolism.

\subsection{The proteomic and chemical analyses revealed unexpected effects of the an1 mutation on the flavonoid pathway}

Previous work had shown that in petunia the messengers for several structural anthocyanin genes rapidly decline after flower opening $[8,35]$. Our proteomic analysis showed that in R27 corolla limbs most of the enzymes of the pathway were still abundant at 1 DAA (Table 1). This observation suggests that structural anthocyanin enzymes are subjected to a slow turnover rate and that anthocyanin synthesis probably still occurs in fully open flowers.

The 5-GTs and AMT enzymes, both involved in anthocyanin decorations, were very abundant in R27 corolla limbs (Table 1). The assignment for three spots to the same sequence encoding for anthocyanin 5-O-glucosyltransferase (5-GTa-c; Table 1 and Fig. 2) evoked the occurrence of PTM. However, they were probably both not functional in R27 flower limbs. In fact, anthocyanins are decorated in petunia by a sequential and strict order of enzymatic reactions dictated by the substrate specificity of each enzyme [35]. The R27 line contains a mutation in $R T$ (Fig. 1; [24]), and therefore both 5-GTs and AMT were expected to be futile enzymes. The fact that cyanidin diglucoside and peonidin glucoside covered respectively only $9 \%$ and $14 \%$ of the total anthocyanins (Table 2), confirmed that both enzymes scarcely work on cyanidin 3-Oglucoside. Hence, it is possible to conceive that the very high abundance of 5-GT in R27 corollas derived from the lack of a feedback inhibition by its end product. Even more interestingly, the decrease in abundance of AMT in the W225 profile is in agreement with the previous observation that the expression of $M F 2$ gene is controlled by AN1 at transcriptional level [35]. According to the analysis presented here, it possible to propose a similar regulation for the gene encoding for the 5-GT. 
The low abundance of enzymes encoded by LBG in W225 corolla limbs compared to the R27 ones (Fig. 1, Table 1) was expected as result of the minor level of the transcripts for these genes in anl mutants [16]. Hence, this last observation represented a good internal control of the validity of our analysis. In line with this, we observed increase in dihydroquercetin (Table 2), the preferential substrate of DFR, in W225. Although DFR and flavonol synthase (FLS) compete for the same substrate [42], the strong increment in dihydroquercetin was not drained off by an upsurge in flavonol biosynthesis. The flavonol content was halved in W225 compared to R27, suggesting that the effect of the $f l$ mutation (Fig. 1) present in both lines is enhanced by the anl mutation. Overall, in an1 W225 flowers the total flavonoid content was lower than in the R27 ones (Table 2). This aspect was also indicated by the decrease of $\mathrm{CHI}$ and F3H enzymes observed in the W225 proteomic profile (Table 1). Since AN1 affects mainly the expression of LBGs [8], the changes at protein level observed for EBGs might be a secondary effect driven by biochemical factors, such as a feedback regulation by the later biosynthetic steps, which probably involve post-translational events. Interestingly, the $\mathrm{CHI}$ electrophoretic position matched with the presence of one phosphorylated site (Table S1). Overall, the an1 mutation did not only affect anthocyanin accumulation but also induced a broad attenuation of the entire flavonoid pathway, probably because it is simultaneously controlled by transcriptional and posttranscriptional mechanisms.

\subsection{The proteomic comparison of R27 and W225 suggested that AN1 affects the course of} corolla senescence

The mutation in AN1 induced changes in the abundance of several proteins, affecting a broad spectrum of pathways in primary metabolism. In particular, several of these changes suggested that the flowers of the two lines differed in physiological traits related to corolla senescence. In petunia, flower senescence is a highly-ethylene sensitive process, considered a subset of developmentally Programmed Cell Death (PCD; $[43,44]$ ), which is required for the remobilization of macromolecules [45].

After anthesis petunia corolla still shows active chloroplasts [46], therefore the lower abundances of enzymes involved in carbon and mitochondrial metabolism in R27 flowers (Table 1) could be indicative of organelle dismantlement, in agreement with the recovery of carbon, nitrogen, and phosphorus observed during corolla senescence [47]. In addition, the higher level of reducing 
sugars in R27 compared to W225 (Table 3) was consistent with active remobilization events in the R27 flowers. Moreover, the decrease of PDX together with two chloroplastic 3PGDHs suggested a general impairment of the amino acid anabolism in the red flowers (Table 1) as well as the joined decreases of CysS, MS and MAT indicated a concomitant lower sulphur assimilation. AlaAT was the only enzyme of this functional class more abundant in R27 flowers. Because AlaAT plays important roles during grain filling in cereals [48], it is tempting to propose a similar role for this enzyme in nitrogen recovery during corolla senescence. The closure of plasmodesmata is one of the earliest ultrastructural changes observed in Iris sepals at the senescence onset [49]. RGP belongs to the class 1 of a family of peripheral plasma membrane proteins, facing the cytoplasmic sleeve of plasmodesmata [50]. It was suggested that RGPs are involved in the regulation of plasmodesmata size exclusion limit [36,51]. Therefore, the higher level of RGP in R27 (Table 1) might be indicative that the cells become isolated from each other in the first phase of corolla senescence also in petunia. Similarly, the observation that several proteins involved in membrane physiology and traffic had a different abundance in R27 and W225 (Table 1) could be indicative of differences in the endomembrane activity between AN1 and an1 corolla limbs. Because mutations that decrease vacuolar acidification do not (or very little) affect the accumulation of anthocyanins in the central vacuole in petunia [11,19], it is rather unlikely that the differences regarding the endomembrane system between R27 and W225 were due to the different vacuolar $\mathrm{pH}$. However, considering the roles of this system in flavonoid metabolism [52] it is not possible to exclude that the different flower flavonoid composition between the two lines affects somehow the endomembranes. Moreover, membrane compartments play an important role in senescence-related processes. In fact, the onset of senescence is associated with cell processes that lead to changes in endomembranes required for the catabolism and translocation of the macromolecules and ultimate in the disassembly of the cell ultrastructure [53]. Therefore, a rearrangement of the endomembrane system fits with a scenario supporting that the flowers of R27 were in a different senescence status respect than those of W225.

Similar considerations might be extended to the enzymes involved in the volatile biosynthesis (Table 1). In fact, benzenoids and phenylpropanoids are the main compounds of petunia flowers bouquet, emitted by corolla epidermal cells after anthesis [54]. Because of their biochemical proximity and the similar physiological function, interlinks are expected to connect the 
anthocyanin and volatile pathways [55]. It is therefore conceivable that BPBT and EGS were somehow affected by the block of the anthocyanin pathway in anl flowers. Additionally, the proteomic trend might be associated with the decline in volatiles production during the last phases of flower life [56]. However, as R27 and derived lines (like W225) are non-fragrant $[40,57]$ it was not possible to verify the effect of such decrease in enzymatic abundance on the volatile bouquet of the anl flowers.

\subsection{The an1 mutation in W225 corolla limbs delayed the onset of senescence process} The integration of the proteomics results (Table 1) with the evaluations of some senescencerelated parameters (Table 3) indicated that at the time of sampling (1 DAA) R27 flowers were at the earlier stages of corolla senescence. Several findings supported this interpretation. First, at 1 DAA flowers did not manifest any wilting symptoms (Fig. 1). Second, R27 flowers accumulated several anthocyanin structural enzymes (Table 1). Third, most of the highlighted processes are generally associated to the early stages of the petal senescence process [44,53]. Fourth, our samples showed no evidences of late events in the senescence process, such as nucleic acid or lipid degradation described by proteomics during the last phase of senescence in petunia corolla $[22]$.

Protein content in corolla generally starts to decrease before symptoms of senescence become visible, and drastically falls under $50 \%$ of the initial value just prior to wilting [58]. Hence, the low difference in protein content between WT and anl corolla limbs (of about $30 \%$, see paragraph 3.1) also supported that at 1 DAA R27 flowers were in an early stage of senescence. Likewise, the higher abundance of both P21 and CP (Table 1) in WT flowers was consistent with the observation that, in petunia flowers, the protease activity does already increase at few DAA, before wilting, and it is mostly ascribed to cysteine proteases [58,59]. At the same time, the decrease in the $\mathrm{R} 27$ profile of CPI, belonging to cystatin family, was in agreement with their role as PCD suppressors [44]. Interestingly, the characterization of anl mutants in petunia has previously highlighted that the expression of an mRNA encoding for a Cys proteinase-like protein (GenBank: AY371317) is strongly decreased in W225 corolla limbs [19].

Our data showed differential accumulation of enzymes of the ascorbate-glutathione cycle (Table 1, Fig. 3). This was not sufficient to support differences in the cell redox status of WT and anl corollas because of the broad functions and redundancy of these enzymes [60]. The biochemical 
512 comparison confirmed the absence of evident osmotic and/or oxidative stresses in both corolla

513 limbs (Table 3). In particular, the similar levels of both total and reduced glutathione discarded

514 the hypothesis that R27 flowers were affected by intense ROS accumulation. Since the oxidative

515 stress is considered a reliable indicator of the transition from early senescence to final PCD [61],

516 this result confirmed that, at 1 DAA, R27 flowers were in a physiological status corresponding to

517 the beginning of senescence progression.

518 In this context, the higher abundance of the ACO protein in the R27 respect to the W225 profile

519 (Table 1) deserves a close examination. In petunia flowers, in the absence of compatible

520 pollination, a late ethylene burst anticipates the first senescence symptoms in ACC-dependent

521 and autocatalytic manner [62]. However, it was also observed that low (basal) ACO1 activity is

522 already present after anthesis as well as the ACO1 induction precedes the ethylene burst [41].

523 Therefore, the higher accumulation of ACO in the R27 profile did not necessarily mirror an

524 advanced phase of corolla senescence but possibly a very early stage of triggering of this

525 process.

526

527

528

4.4. The an1 mutation enhanced flower longevity in planta and made cut flowers

insensitive to sugar feeding

529 The enhancement of flower longevity in planta in W225, as compared to R27 (Table 4),

530 provided the strongest confirmation that the anl mutation affected the senescence status of the

531 flowers, probably resulting in the slowing down of the process. Considering the prominent roles

532 played by the vacuole during initiation and execution of cell senescence [53], the results opens the question of whether the AN1 transcription factor is directly involved in senescence timing or,

534 alternatively, the longer life of W225 flowers is a secondary effect linked to the alteration of

535 vacuolar $\mathrm{pH}$. The responses of cut flowers to sugar feeding gave new insights into this issue.

536 The R27 flowers resulted as a good example of the "sugar paradox" described in many floral

537 species [44]. Even if sugar levels were high at the onset of senescence (Table 3), the exogenous

538 sucrose delayed the time of wilting, restoring a life span comparable to the one of uncut flowers.

539 On the contrary, the W225 flowers were not affected by sugar feeding, and the longevity

540 decrease caused by detachment resulted irreversible (Table 4). As the sugars have a considerably

541 stronger effect on ethylene-sensitive species, it was proposed that they act as anti-ethylene signal

542 [44]. Therefore, R27 appeared as a typical ethylene-sensitive line while W255 showed a 
543 behaviour resembling non-sensitive species. This aspect was also consistent with the minor 544 accumulation of ACO in W225 corolla limbs (Table 1), which is probably related to a lessening

545 in the ethylene metabolism in the white flowers. Taken together, the results suggest that AN1

546 could somehow be involved in ethylene perception.

\section{Conclusions}

549 This study shows that proteomic investigation combined with biochemical and physiological 550 approach is suitable for the study of genetic pleiotropy. We report that the AN1 gene also affects 551 the abundance of proteins whose genes were previously shown to be transcribed in an AN1552 independent fashion. This broadens our knowledge about the regulatory network that includes

553 the flavonoid pathway, and it supports the occurrence of both (post)transcriptional and

554 biochemical mechanisms. Moreover, this study provides new proteomic and biochemical insights

555 into the factors participating in flower senescence. At the same time, the biochemical and

556 physiological analyses show that the pigmentation regulator AN1 affects also floral longevity

557 and the responses to sugar feeding of cut flowers. AN1 is a component of the WD40-bHLH-

558 MYB complex of transcription factors, which is widely conserved among much unrelated plant

559 species and involved in several aspects of epidermal cells differentiation. Therefore, this work

560 suggests novel roles for the AN1 transcription factor, revealing unexpected relations between the 561 regulation of epidermal cell fate and hormonal balance.

562

\section{Supplementary data}

564 Fig. S1 2-DE profiles of total protein fraction from corolla limbs of the Petunia hybrida AN1 565 (R27) and anl (W225) lines at 1 day after anthesis.

566 Fig. S2 Volcano plot showing the distribution of the spot variations derived from the comparison 567 of W225 and R27 lines.

568 Fig. S3 Visual evaluation of flower longevity in Petunia hybrida AN1 (R27) and an1 (W225)

569 lines.

570 Table S1 Detailed information and statistical data about protein characterization by nLC-nESI$571 \mathrm{MS} / \mathrm{MS}$.

572

573 Abbreviations 
574 ACN, acetonitrile; AN1, ANTHOCYANIN1; bHLH, basic Helix-Loop-Helix; cCBB, colloidal

575 Coomassie Brilliant Blue G-250; DAA, day after anthesis; DFR, dihydroflavonol 4-reductase;

576 EBG, Early Biosynthetic Genes; FA, formic acid; FLS, flavonol synthase; GSH, reduced

577 glutathione; GSSG, oxidized glutathione; LBG, Late Biosynthetic Genes; PCD, Programmed

578 Cell Death; RT, anthocyanin rhamnosyl transferase; WT, wild type.

579

580

\section{Conflict of interest statement}

581 The authors declare that the research was conducted in the absence of any commercial or

582 financial relationships that could be construed as a potential conflict of interest.

583

584

\section{References}

585

[1] Winkel BSJ. The biosynthesis of flavonoids. In: Grotewold E, editor. The science of flavonoids. New York, NY: Springer; 2006, p. 71-95.

587 [2] Taylor LP, Grotewold E. Flavonoids as developmental regulators. Curr Opin Plant Biol 588 2005;8:317-23.

589 [3] Falcone Ferreyra ML, Rius SP, Casati P. Flavonoids: biosynthesis, biological functions, and biotechnological applications. Front Plant Sci 2012;3:222.

591 [4] Gerats T, Vandenbussche M. A model system for comparative research: Petunia. Trends $592 \quad$ Plant Sci 2005;10:251-6.

593 [5] Koes R, Verweij W, Quattrocchio F. Flavonoids: a colorful model for the regulation and 594 evolution of biochemical pathways. Trends Plant Sci 2005;10:236-42.

[6] Tornielli G, Koes R, Quattrocchio F. The genetics of flower color. In: Gerats T, Strommer J, editors. Petunia: Evolutionary, Developmental and Physiological Genetics. Heidelberg, Germany: Springer; 2009, p.269-300.

601

[7] Holton TA, Cornish EC. Genetics and biochemistry of anthocyanin biosynthesis. Plant Cell 1995;7:1071-83.

[8] Quattrocchio F, Wing JF, Leppen HTC, Mol JNM, Koes R. Regulatory genes controlling 602 anthocyanin pigmentation are functionally conserved among plant species and have distinct sets of target genes. Plant Cell 1993;5:1497-512. 
[9] Alfrenito MR, Souer E, Goodman CD, Buell R, Mol J, Koes R, Walbot V. Functional complementation of anthocyanin sequestration in the vacuole by widely divergent glutathione S-transferase. Plant Cell 1998;10:1135-49.

[10] Mueller LA, Goodman CD, Silady RA, Walbot V. AN9, a petunia glutathione S-transferase required for anthocyanin sequestration, is a flavonoid-binding protein. Plant Physiol 2000,123:1561-70.

[11] Verweij W, Spelt C, Di Sansebastiano GP, Vermeer J, Reale L, Ferranti F, Koes R, Quattrocchio F. An $\mathrm{H}^{+}$P-ATPase on the tonoplast determines vacuolar $\mathrm{pH}$ and flower colour. Nat Cell Biol 2008;10:1456-62.

[12] Faraco M, Spelt C, Bliek M, Verweij W, Hoshino A, Espen L, Prinsi B, Jaarsma R, Tarhan E, de Boer AH, Di Sansebastiano G-P, Koes R, Quattrocchio FM. Hyperacidification of vacuoles by the combined action of two different P-ATPases in the tonoplast determines flower color. Cell Rep 2014;6:32-43.

[13] Quattrocchio F, Wing JF, van der Woude K, Mol JN, Koes R. Analysis of bHLH and MYBdomain proteins: species-specific regulatory differences are caused by divergent evolution of target anthocyanin genes. Plant J 1998;13:475-88.

[14] Schwinn K, Venail J, Shang Y, Mackay S, Alm V, Butelli E, Oyama R, Bailey P, Davies K, Martin C. A small family of $M Y B$-regulatory genes controls floral pigmentation intensity and patterning in the genus Antirrhinum. Plant Cell 2006;18:831-51.

[15] Petroni K, Tonelli C. Recent advances on the regulation of anthocyanin synthesis in reproductive organs. Plant Sci 2011;181:219-29.

[16] Spelt C, Quattrocchio F, Mol JNM, Koes R. anthocyanin1 of petunia encodes a basic HelixLoop-Helix protein that directly activates transcription of structural anthocyanin genes. Plant Cell 2000;12:1619-31.

[17] Albert NW, Lewis DH, Zhang H, Schwinn KE, Jameson PE, Davies KM. Members of an R2R3-MYB transcription factor family in Petunia are developmentally and environmentally regulated to control complex floral and vegetative pigmentation patterning. Plant J 2011;65: 771-84.

[18] Spelt C, Quattrocchio F, Mol JNM, Koes R. ANTHOCYANIN1 of Petunia controls pigment synthesis, vacuolar $\mathrm{pH}$, and seed coat development by genetically distinct mechanisms. Plant Cell 2002;14:2121-35. 
[19] Quattrocchio F, Verweij W, Kroon A, Spelt C, Mol J, Koes R. PH4 of petunia is a R2R3 MYB protein that activates vacuolar acidification through interactions with basic-HelixLoop-Helix transcription factors of the anthocyanin pathway. Plant Cell 2006;18:1274-91.

[20] Negri AS, Prinsi B, Rossoni M, Failla O, Scienza A, Cocucci M, Espen L. Proteome changes in the skin of the grape cultivar Barbera among different stages of ripening. BMC Genomics 2008;9:378.

[21]Dafny-Yelin M, Guterman I, Menda N, Ovadis M, Shalit M, Pichersky E, Zamir D, Lewinsohn E, Adam Z, Weiss D, Vainstein A. Flower proteome: changes in protein spectrum during the advanced stages of rose petal development. Planta 2005;222:37-46.

[22] Bai S, Willard B, Chapin LJ, Kinter MT, Francis DM, Stead AD, Jones ML. Proteomic analysis of pollination-induced corolla senescence in petunia. J Exp Bot 2010;61:1089-109.

[23] Holton TA, Brugliera F, Lester DR, Tanaka Y, Hyland GD, Menting JGT, Lu C-Y, Farcy E, Stevenson TW, Cornish EC. Cloning and expression of cytochrome P450 genes controlling flower colour. Nature 1993;336:276-9.

[24] Kroon J, Souer E, de Graaff A, Xue Y, Mol Y, Koes R. Cloning and structural analysis of the anthocyanin pigmentation locus Rt of Petunia hybrida: characterization of insertion sequences in two mutant alleles. Plant J 1994;5:69-80.

[25] Gerats AGM, de Vlaming P, Doodeman M, Schram AW. Genetic control of the conversion of dihydroflavonols into flavonols and anthocyanins in flowers of Petunia hybrida. Planta 1982;155:364-8.

[26] Hermann K, Klahre U, Moser M, Sheehan H, Mandel T, Kuhlemeier C. Tight genetic linkage of prezygotic barrier loci creates a multifunctional speciation island in Petunia. Curr Biol 2013;23:873-7.

[27] de Vlaming P, Cornu A, Farcy E, Gerats AGM, Maizonnier D, Wiering H, Wijsman HJW. Petunia hybrida: a short description of the action of 91 genes, their origin and their map location. Plant Mol Biol Report 1984;2:21-42.

[28] Prinsi B, Negri AS, Fedeli C, Morgutti S, Negrini N, Cocucci M, Espen L. Peach fruit ripening: a proteomic comparative analysis of the mesocarp of two cultivars with different flesh firmness at two ripening stages. Phytochemistry 2011;72:1251-62. 
[29] Mackey AJ, Haystead TA, Pearson WR. Getting more from less: algorithms for rapid protein identification with multiple short peptide sequences. Mol Cell Proteomics 2002, $1: 139-47$.

[30] Nelson NA. A photometric adaptation of the Somogyi method for the determination of glucose. J Biol Chem 1944;153:375-84.

[31] Prinsi B, Negri AS, Pesaresi P, Cocucci M, Espen L. Evaluation of protein pattern changes in roots and leaves of Zea mays plants in response to nitrate availability by two-dimensional gel electrophoresis analysis. BMC Plant Biol 2009;9:113.

[32] Van Tunen AJ, Koes RE, Spelt CE, van der Krol AR, Stuitje AR, Mol JNM. Cloning of two chalcone flavanone isomerase genes from Petunia hybrida: coordinated, light-regulated and differential expression of flavonoid genes. EMBO J 1988;7:1257-63.

[33] Britsch L, Grisebach H. Purification and characterization of (2S)-flavanone 3-hydroxylase from Petunia hybrida. Eur J Biochem 1986;156:569-77.

[34] Beld M, Mertin C, Huits H, Stuitje AR, Gerats AGM. Flavonoid synthesis in Petunia hybrida: partial characterization of dihydroflavonol-4-reductase genes. Plant Mol Biol 1989;13:491-502.

[35] Provenzano S, Spelt C, Hosokawa S, Nakamura N, Brugliera F, Demelis L, Geerke DP, Schubert A, Tanaka Y, Quattrocchio F, Koes R. Genetic control and evolution of anthocyanin methylation. Plant Physiol 2014;165:962-77.

[36] Burch-Smith TM, Cui Y, Zambryski PC. Reduced levels of class 1 reversibly glycosylated polypeptide increase intercellular transport via plasmodesmata. Plant Signal Behav 2012;7:62-7.

[37] Park JJ, Jin P, Yoon J, Yang JI, Jeong HJ, Ranathunge K, Schreiber L, Franke R, Lee IJ, An G. Mutation in Wilted Dwarf and Lethal 1 (WDL1) causes abnormal cuticle formation and rapid water loss in rice. Plant Mol Biol 2010;74:91-103.

[38] Batoko H, Zheng HQ, Hawes C, Moore I. A rab1 GTPase is required for transport between the endoplasmic reticulum and Golgi apparatus and for normal Golgi movement in plants. Plant Cell 2000;12:2201-18.

[39] de Graaf BH, Cheung AY, Andreyeva T, Levasseur K, Kieliszewski M, Wu HM. Rab11 GTPase-regulated membrane trafficking is crucial for tip-focused pollen tube growth in tobacco. Plant Cell 2005;17:2564-79. 
[40] Koeduka T, Louie GV, Orlova I, Kish CM, Ibdah M, Wilkerson CG, Bowman ME, Baiga TJ, Noel JP, Dudareva N, Pichersky E. The multiple phenylpropene synthases in both Clarkia breweri and Petunia hybrida represent two distinct protein lineages. Plant J 2008;54:362-74.

[41] Tang X, Gomes AMTR, Bhatia A, Woodson WR. Pistil-specific and ethylene-regulated expression of 1-aminocyclopropane-1 carboxylate oxidase genes in Petunia flowers. Plant Cell 1994;6:1227-39.

[42] Holton TA, Brugliera F, Tanaka Y. Cloning and expression of flavonol synthase from Petunia hybrida. Plant J 1993;4:1003-10.

[43] van Doorn WG. Categories of petal senescence and abscission: a re-evaluation. Ann Bot 2001;87:447-56.

[44] van Doorn WG, Woltering EJ. Physiology and molecular biology of petal senescence. J Exp Bot 2008;59:453-80.

[45] Jones ML. Mineral nutrient remobilization during corolla senescence in ethylene-sensitive and -insensitive flowers. AoB PLANTS 2013;5:plt023.

[46] Weiss D, Schonfeld M, Halevy AH. Photosynthetic activities in the petunia corolla. Plant Physiol 1988;87:666-70.

[47] Verlinden S. Changes in mineral nutrient concentrations in petunia corollas during development and senescence. HortScience 2003;38:71-4.

[48] Masclaux-Daubresse C, Daniel-Vedele F, Dechorgnat J, Chardon F, Gaufichon L, Suzuki A. Nitrogen uptake, assimilation and remobilization in plants: challenges for sustainable and productive agriculture. Ann Bot 2010;105:1141-57.

[49] van Doorn WG, Balk PA, van Houwelingen AM, Hoeberichts FA, Hall RD, Vorst O, van der Schoot C, van Wordragen MF. Gene expression during anthesis and senescence in Iris flowers. Plant Mol Biol 2003;53:845-63.

[50] Sagi G, Katz A, Guenoune-Gelbart D, Epel BL. Class 1 reversibly glycosylated polypeptides are plasmodesmal-associated proteins delivered to plasmodesmata via the Golgi apparatus. Plant Cell 2005; 17:1788-800.

[51]Zavaliev R, Sagi G, Gera A, Epel BL. The constitutive expression of Arabidopsis plasmodesmal-associated class 1 reversibly glycosylated polypeptide impairs plant development and virus spread. J Exp Bot 2010;61:131-42. 
[52]Zhao J, Dixon RA. The ‘ins' and 'outs' of flavonoid transport. Trends Plant Sci 2010;15:7280 .

[53] Hopkins M, Taylor C, Liu Z, Ma F, McNamara L, Wang TW, Thompson JE. Regulation and execution of molecular disassembly and catabolism during senescence. New Phytol 2007;175:201-14.

[54] Colquhoun TA, Verdonk JC, Schimmel BCJ, Tieman DM, Underwood BA, Clark DG. Petunia floral volatile benzenoid/phenylpropanoid genes are regulated in a similar manner. Phytochemistry 2010;71:158-67.

[55]Zvi MMB, Negre-Zakharov F, Masci T, Ovadis M, Shklarman E, Ben-Meir H, Tzfira T, Duradeva N, Vainstein A. Interlinking showy traits: co-engineering of scent and colour biosynthesis in flowers. Plant Biotech J 2008;6:403-15.

[56] Underwood BA, Tieman DM, Shibuya K, Dexter RJ, Loucas HM, Simkin AJ, Sims CA, Schmelz EA, Klee HJ, Clark DG. Ethylene-regulated floral volatile synthesis in petunia corollas. Plant Physiol 2005;138:255-66.

[57] Van Moerkercke A, Haring MA, Schuurink RC. The transcription factor EMISSION OF BENZENOIDS II activates the MYB ODORANT1 promoter at a MYB binding site specific for fragrant petunias. Plant J 2011;67:917-28.

[58] Jones ML, Chaffin GS, Eason JR, Clark DG. Ethylene-sensitivity regulates proteolytic activity and cysteine protease gene expression in petunia corollas. J Exp Bot 2005;56:273344.

[59] Tournaire C, Kushnir S, Bauw G, Inzé D, Teyssendier de la Serve B, Renaudin JP. A thiol protease and an anionic peroxidase are induced by lowering cytokinins during callus growth in Petunia. Plant Physiol 1996;111:159-68.

[60] Foyer CH, Noctor G. Ascorbate and glutathione: the heart of the redox hub. Plant Physiol 2011;155:2-18.

[61] Rogers HJ. Is there an important role for reactive oxygen species and redox regulation during floral senescence? Plant Cell Environ 2012;35:217-33.

[62] Singh A, Evensen KB, Kao T. Ethylene synthesis and floral senescence following compatible and incompatible pollinations in Petunia infilata. Plant Physiol 1992;99:38-45. 
754 Table 1 Identification and quantification of the spots differentially accumulated in corolla limbs

755 of Petunia hybrida AN1 (R27) and an1 (W225) lines (at 1 day after anthesis), sorted according to

756 the functional classes in Fig. 3.

\begin{tabular}{|c|c|c|c|c|c|c|}
\hline $\mathbf{N}^{\mathrm{a}}$ & Acronym $^{b}$ & Accession Species & Protein description & $\begin{array}{c}\% \text { Vol }^{\mathrm{c}} \\
\text { R27 }\end{array}$ & $\begin{array}{l}\% \text { Vol }^{\mathrm{c}} \\
\text { W225 }\end{array}$ & $\begin{array}{c}\Delta \\
\mathbf{W} 225 / \mathbf{R} 27 \\
\end{array}$ \\
\hline \multicolumn{7}{|c|}{ Anthocyanin metabolism } \\
\hline 1596 & CHI & P11650 P. hybrida & Chalcone isomerase A & $0.306 \pm 0.015$ & $0.074 \pm 0.015$ & 0.24 \\
\hline 1024 & F3H & Q07353 P. hybrida & Flavanone 3-hydroxylase & $0.488 \pm 0.011$ & $0.243 \pm 0.026$ & 0.50 \\
\hline 809 & DFR & P14720 P. hybrida & Dihydroflavonol 4-reductase & $0.146 \pm 0.006$ & $0.073 \pm 0.003$ & 0.50 \\
\hline 744 & 5-GTa & BAA89009 P. hybrida & Anthocyanin 5-O-glucosyltransferase & $0.171 \pm 0.018$ & $0.082 \pm 0.004$ & 0.48 \\
\hline 761 & 5-GTb & BAA89009 P. hybrida & Anthocyanin 5-O-glucosyltransferase & $0.297 \pm 0.013$ & $0.068 \pm 0.004$ & 0.23 \\
\hline 776 & 5-GTc & BAA89009 P. hybrida & Anthocyanin 5-O-glucosyltransferase & $0.553 \pm 0.016$ & $0.052 \pm 0.008$ & 0.09 \\
\hline 1610 & AMT & AIE77046 P. hybrida & Anthocyanin methyltransferase & $0.958 \pm 0.031$ & $0.183 \pm 0.012$ & 0.19 \\
\hline 1582 & AN9 & CAA68993 P. hybrida & Glutathione S-transferase & $0.184 \pm 0.009$ & $0.048 \pm 0.013$ & 0.26 \\
\hline \multicolumn{7}{|c|}{ Carbon metabolism } \\
\hline 624 & RuBisCO & P04992 P. hybrida & RuBisCO large subunit & $0.067 \pm 0.016$ & $0.350 \pm 0.044$ & 5.23 \\
\hline 497 & HSP60a & AAB39827 S. tuberosum & Chaperonin- 60 beta subunit & $0.051 \pm 0.005$ & $0.159 \pm 0.023$ & 3.09 \\
\hline 655 & 6PGD & BAA22812 G. $\max$ & 6-phosphogluconate dehydrogenase & $0.040 \pm 0.004$ & $0.331 \pm 0.012$ & 8.34 \\
\hline 284 & TKa & CAA75777 C. annum & Transketolase 1 & $0.047 \pm 0.006$ & $0.119 \pm 0.012$ & 2.56 \\
\hline 285 & TKb & CAA75777 C. annum & Transketolase 1 & $0.088 \pm 0.005$ & $0.302 \pm 0.029$ & 3.44 \\
\hline 348 & PGMa & Q9M4G4 S. tuberosum & Phosphoglucomutase cytoplasmic & $0.066 \pm 0.004$ & $0.161 \pm 0.009$ & 2.46 \\
\hline 354 & PGMb & Q9M4G4 S. tuberosum & Phosphoglucomutase cytoplasmic & $0.115 \pm 0.005$ & $0.326 \pm 0.020$ & 2.83 \\
\hline 957 & FBPA & ABC01905 S. tuberosum & Fructose-bisphosphate aldolase & $0.103 \pm 0.015$ & $0.212 \pm 0.012$ & 2.06 \\
\hline \multicolumn{7}{|c|}{ Mitochondrial metabolism } \\
\hline 780 & CS & P20115 Arabidopsis thaliana & Citrate synthase 4 , mitochondrial & $0.109 \pm 0.008$ & $0.305 \pm 0.025$ & 2.80 \\
\hline 123 & АСОНа & BAG16527 C. chinense & Putative aconitase & $0.143 \pm 0.013$ & $0.466 \pm 0.027$ & 3.26 \\
\hline 124 & ACOHb & BAG16527 C. chinense & Putative aconitase & $0.023 \pm 0.007$ & $0.078 \pm 0.005$ & 3.37 \\
\hline 127 & АСОНс & BAG16527 C. chinense & Putative aconitase & $0.146 \pm 0.013$ & $0.425 \pm 0.022$ & 2.92 \\
\hline 122 & ACOHd & AAG28426 N. tabacum & Cytosolic aconitase & $0.057 \pm 0.005$ & $0.176 \pm 0.012$ & 3.09 \\
\hline 785 & IDH & P50218 N. tabacum & Isocitrate dehydrogenase [NADP] & $0.042 \pm 0.007$ & $0.197 \pm 0.015$ & 4.65 \\
\hline 457 & HSP60b & P29197 A. thaliana & Chaperonin CPN60, mitochondrial & $0.080 \pm 0.002$ & $0.229 \pm 0.015$ & 2.87 \\
\hline 108 & GDH & O49954 S. tuberosum & Glycine dehydrogenase, mitoc. & $0.012 \pm 0.003$ & $0.092 \pm 0.009$ & 7.94 \\
\hline 473 & LDH & AAS47493 C. annum & Lipoamide dehydrogenase & $0.059 \pm 0.007$ & $0.165 \pm 0.008$ & 2.78 \\
\hline 395 & OXC & CAN69570 V. vinifera & Oxalyl-CoA decarboxylase ${ }^{\mathrm{e}}$ & $0.030 \pm 0.010$ & $0.121 \pm 0.007$ & 4.02 \\
\hline \multicolumn{7}{|c|}{ Amino acid metabolism } \\
\hline 1247 & PDX & AAS92255 N. tabacum & Pyridoxine biosynthesis isoform A & $0.038 \pm 0.004$ & $0.095 \pm 0.010$ & 2.50 \\
\hline 425 & 3PGDHa & XP_002273552 V. vinifera & D-3-phosphoglycerate dehydrogenase & $0.034 \pm 0.008$ & $0.100 \pm 0.006$ & 2.92 \\
\hline 461 & 3PGDHb & XP_002300235 P. trichocarpa & D-3-phosphoglycerate dehydrogenase ${ }^{\mathrm{f}}$ & $0.040 \pm 0.006$ & $0.118 \pm 0.005$ & 2.92 \\
\hline 1204 & CysS & CAJ32462 N. tabacum & Put. cytosolic cysteine synthase 7 & $0.030 \pm 0.006$ & $0.118 \pm 0.014$ & 3.97 \\
\hline 207 & MS & AAF74983 S. tuberosum & Methionine synthase & $0.130 \pm 0.013$ & $0.412 \pm 0.025$ & 3.18 \\
\hline 771 & MAT & P43282 S. lycopersicum & S-adenosylmethionine synthase 3 & $0.094 \pm 0.010$ & $0.282 \pm 0.015$ & 3.00 \\
\hline 642 & AlaAT & AAR05449 C. annum & Alanine aminotransferase & $0.158 \pm 0.015$ & $0.028 \pm 0.018$ & 0.18 \\
\hline \multicolumn{7}{|c|}{ Endomembrane system } \\
\hline 1077 & RGP & ABG76000 G. hirsutum & RGP-like protein 2 & $0.204 \pm 0.009$ & $0.079 \pm 0.027$ & 0.39 \\
\hline 1190 & SGNH & XP_002325360 P. trichocarpa & SGNH-plant lipase like ${ }^{\mathrm{f}}$ & $0.231 \pm 0.019$ & $0.048 \pm 0.017$ & 0.21 \\
\hline 1674 & Rab1 & AAD10389 P. hybrida & Rab1-like small GTP-binding protein & $0.081 \pm 0.002$ & $0.038 \pm 0.006$ & 0.47 \\
\hline 1459 & Rab11 & AAA74116 N. tabacum & Rab11-like ${ }^{f}$ & $0.082 \pm 0.005$ & n.d. & $-\infty$ \\
\hline 261 & RK & XP_002305880 P. trichocarpa & Putative receptor kinase ${ }^{\mathrm{e}}$ & $0.061 \pm 0.009$ & n.d. & $-\infty$ \\
\hline 1322 & $22 P$ & CAA65195 N. tabacum & $22 \mathrm{kDa}$ polypeptide & $0.135 \pm 0.006$ & $0.378 \pm 0.026$ & 2.81 \\
\hline 277 & NSF & BAA13101 N. tabacum & NEM sensitive fusion protein & $0.026 \pm 0.008$ & $0.112 \pm 0.007$ & 4.28 \\
\hline 1126 & CLIC & ABC75353 M. truncatula & Intracellular chloride channel & $0.045 \pm 0.005$ & $0.184 \pm 0.009$ & 4.05 \\
\hline
\end{tabular}




\begin{tabular}{|c|c|c|c|c|c|c|}
\hline \multicolumn{7}{|c|}{ Volatile biosynthesis } \\
\hline 524 & BPBT & AAU06226 P. hybrida & Benzyl alcohol O-benzoyltransferase & $0.093 \pm 0.010$ & $0.255 \pm 0.031$ & 2.74 \\
\hline 1216 & EGSa & ABR24115 P. hybrida & Eugenol synthase 1 & $0.579 \pm 0.015$ & $0.066 \pm 0.006$ & 0.11 \\
\hline 1221 & EGSb & ABR24115 P. hybrida & Eugenol synthase 1 & $0.040 \pm 0.009$ & $0.404 \pm 0.039$ & 10.22 \\
\hline \multicolumn{7}{|c|}{ Protein turnover } \\
\hline 1548 & P21 & AAC49361 P. hybrida & $\mathrm{P} 21$ & $0.058 \pm 0.002$ & n.d. & $-\infty$ \\
\hline 886 & $\mathbf{C P}$ & AAU81589 P. hybrida & Cysteine proteinase & $0.092 \pm 0.020$ & $0.009 \pm 0.009$ & 0.10 \\
\hline 1766 & CPI & AAU81597 P. hybrida & Cysteine proteinase inhibitor & n.d. & $0.108 \pm 0.021$ & $+\infty$ \\
\hline 1536 & PSa & Q9XG77 N. tabacum & Proteasome subunit alpha type- 6 & $0.044 \pm 0.004$ & $0.128 \pm 0.008$ & 2.90 \\
\hline 362 & GtRNAS & XP_002297878 P. trichocarpa & Glycyl-tRNA synthetase ${ }^{f}$ & $0.027 \pm 0.003$ & $0.102 \pm 0.004$ & 3.72 \\
\hline 312 & OPD & XP_002527223 R. communis & Oligopeptidase A, putative & $0.109 \pm 0.002$ & $0.016 \pm 0.007$ & 0.15 \\
\hline \multicolumn{7}{|c|}{ Redox status } \\
\hline 1665 & GSTa & P46423 H. muticus & Glutathione $S$-transferase & $0.280 \pm 0.011$ & $0.099 \pm 0.008$ & 0.35 \\
\hline 1768 & GSTb & P46423 H. muticus & Glutathione $S$-transferase & n.d. & $0.031 \pm 0.007$ & $+\infty$ \\
\hline 531 & GSR & ABW96363 I. batatas & Glutathione reductase & $0.054 \pm 0.004$ & $0.132 \pm 0.011$ & 2.46 \\
\hline 896 & MDARa & Q43497 S. lycopersicum & Monodehydroascorbate reductase & $0.601 \pm 0.043$ & $0.100 \pm 0.033$ & 0.17 \\
\hline 1767 & MDARb & Q43497 S. lycopersicum & Monodehydroascorbate reductase & n.d. & $0.399 \pm 0.035$ & $+\infty$ \\
\hline \multicolumn{7}{|c|}{ Hormone biosynthesis } \\
\hline 1070 & $\mathrm{ACO}$ & BAF33504 O. minor & ${\text { ACC } \text { oxidase }^{g}}^{g}$ & $0.244 \pm 0.010$ & $0.106 \pm 0.007$ & 0.44 \\
\hline
\end{tabular}

$758{ }^{a}$ Spot number refers to supplementary Table S1 reporting statistical data about nLC-nESI-

759 MS/MS analysis.

$760{ }^{\mathrm{b}}$ Acronyms refer to Figure 2.

$761{ }^{\mathrm{c}}$ Spot volume \pm SE.

$762{ }^{\mathrm{d}}$ Volume change in $\mathrm{W} 225$ relative to $\mathrm{R} 27$.

$763{ }^{\mathrm{e}}$ Annotation by BLAST alignment against nr-NCBI.

$764{ }^{\mathrm{f}}$ Annotation suggested by the authors.

$765{ }^{\mathrm{g}}$ Annotation rectified by BLAST alignment against nr-NCBI. 
Table 2 Levels of flavonoids in corolla limbs of Petunia hybrida AN1 (R27) and an1 (W225)

767 lines at 1 day after anthesis.

\begin{tabular}{|c|c|c|c|}
\hline & \multirow{2}{*}{$\begin{array}{c}\text { Molecular ion - Fragment ion } \\
\left(\mathbf{M}^{+} \mathbf{m} / \mathbf{z}\right)\end{array}$} & \multicolumn{2}{|c|}{$\mu \mathrm{mol} \mathrm{g}^{-1} \mathrm{FW}^{\mathrm{c}}$} \\
\hline & & $\mathbf{R 2 7}$ & W225 \\
\hline Flavanones & & $0.48 \pm 0.05$ & $0.84 \pm 0.04$ \\
\hline Eriodictyol $^{\mathrm{b}}$ & 289.07 & $0.48 \pm 0.05$ & $0.38 \pm 0.02$ \\
\hline Eriodictyol glucoside $^{\mathrm{b}}$ & $451.12-289.07$ & & $0.45 \pm 0.02$ \\
\hline Dihydroflavonols & & $1.08 \pm 0.10$ & $3.06 \pm 0.30$ \\
\hline Dihydroquercetin & 305.07 & $0.62 \pm 0.07$ & $2.09 \pm 0.24$ \\
\hline Dihydroquercetin glucoside & $467.12-305.07$ & $0.46 \pm 0.03$ & $0.97 \pm 0.06$ \\
\hline Flavonols & & $3.20 \pm 0.40$ & $1.71 \pm 0.05$ \\
\hline Quercetin & 303.05 & $0.36 \pm 0.01$ & \\
\hline Quercetin glucoside ${ }^{b}$ & 465.10 & $0.54 \pm 0.03$ & $0.34 \pm 0.01$ \\
\hline Quercetin diglucoside & $627.16-465.10-303.05$ & $0.96 \pm 0.14$ & $0.60 \pm 0.07$ \\
\hline Quercetin triglucoside & $789.21-627.16-465.10$ & $1.34 \pm 0.21$ & $0.77 \pm 0.02$ \\
\hline Anthocyanins & & $2.95 \pm 0.26$ & \\
\hline Cyanidin glucoside $^{\mathrm{b}}$ & $449.11-287.06$ & $1.40 \pm 0.11$ & \\
\hline Cyanidin diglucoside $^{\mathrm{b}}$ & $611.16-449.11-287.06$ & $0.89 \pm 0.14$ & \\
\hline Cyanidin triglucoside & $773.21-611.16-449.11$ & $0.27 \pm 0.01$ & \\
\hline Peonidin glucoside & $463.12-301.07$ & $0.40 \pm 0.01$ & \\
\hline TOTAL & & $7.72 \pm 0.80$ & $5.61 \pm 0.39$ \\
\hline
\end{tabular}

768

$769{ }^{a}$ Molecular ion - Fragment ion, fragmentation pattern detected by nLC-nESI-MS/MS and used

770 for the compound identification; $\mathrm{M}^{+}$, molecule with a single positive charge.

$771{ }^{\mathrm{b}}$ Compounds were assigned by fragmentation pattern and/or retention time of standards.

$772{ }^{c}$ Values are the mean $\pm \mathrm{SE}, \mathrm{n}=3$. Amounts of each class and total flavonoids are reported in

773 bold. The difference of each flavonoid class between R27 and W225 was significant according to 774 the Student's t-test $(\mathrm{p}<0.05)$. 
775 Table 3 Biochemical evaluation of senescence-related parameters in flowers of Petunia hybrida $776 \quad A N 1$ (R27) and anl (W225) lines at 1 day after anthesis.

\begin{tabular}{|c|c|c|}
\hline & $\mathbf{R 2 7}$ & W225 \\
\hline Limb fresh weight $(g)^{a}$ & $0.143 \pm 0.002$ & $0.144 \pm 0.003$ \\
\hline Limb water content $(\%)^{a}$ & $89 \pm 1$ & $90 \pm 1$ \\
\hline GSH + 2GSSG $\left(\mathrm{nmol} \mathrm{g}^{-1} \mathbf{F W}\right)^{b}$ & $34.76 \pm 1.86$ & $32.84 \pm 2.53$ \\
\hline GSH (\%) of total glutathione ${ }^{b}$ & $89.2 \pm 2.1$ & $86.7 \pm 2.0$ \\
\hline Reducing sugars $\left(\mu \mathrm{mol} \mathrm{g}^{-1} \mathbf{F W}\right)^{b}$ & $119.36 \pm 2.23^{\mathrm{c}}$ & $77.11 \pm 4.52^{\mathrm{c}}$ \\
\hline Sucrose $\left(\mu \mathrm{mol} \mathrm{g}{ }^{-1} \mathbf{F W}\right)^{b}$ & $6.88 \pm 2.10$ & $9.72 \pm 4.01$ \\
\hline
\end{tabular}

777

$778{ }^{\text {a }}$ Values are the mean \pm SE of 5 independent pools $(n=5)$, each composed by 5 flowers.

$779{ }^{\mathrm{b}}$ Values are the mean $\pm \mathrm{SE}, \mathrm{n}=6$.

$780{ }^{\mathrm{c}}$ The difference is significant according to the Student's t-test $(\mathrm{p}<0.01)$. 
781 Table 4 Longevity of in planta and cut flowers of AN1 (R27) and an1 (W225) plants. The values 782 reported are the hours from anthesis to the appearance of visible corolla wilting symptoms.

783

\begin{tabular}{lcc}
\hline & R27 (h) & W225 (h) \\
\hline In planta & $72.0 \pm 1.1(\mathrm{~b})$ & $123.3 \pm 2.9(\mathrm{c})$ \\
Cut flowers in water & $55.3 \pm 1.8(\mathrm{a})$ & $70.7 \pm 1.3(\mathrm{~b})$ \\
Cut flowers in 10 mM sucrose & $72.7 \pm 0.7$ (b) & $73.3 \pm 1.3(\mathrm{~b})$ \\
\hline
\end{tabular}

784

785 Values are the mean \pm SE of six flowers analysed in triplicate $(n=3)$. The significance was

786 assessed through factorial ANOVA test ( $\mathrm{p}<0.01$, Tukey post hoc test).

787 


\section{Figure captions}

789 Fig. 1 - Phenotypic and genetic characters of the Petunia hybrida lines. (a) Flower feature and pH of petal cell sap in R27 and W225 lines. (b) Simplified scheme of the flavonoid pathway in the R27 genetic background. The enzymes (and relative products) encoded by mutated gene are reported in grey. W225 harbours a mutation in the AN1 gene, encoding a transcription factor that controls Late Biosynthetic Genes (indicated by bracket) and vacuolar acidification. CHS:

794 chalcone synthase; CHI: chalcone isomerase; F3'5'H: flavonoid 3'5' hydroxylase; FS: flavone synthase; F3H: flavonoid 3-hydroxylase; F3'H: flavanone 3'-hydroxylase; FLS: flavonol synthase; DFR: dihydroflavonol 4-reductase; LDOX: leucoanthocyanidin dioxygenase; ANS: anthocyanidin synthase; 3-GT: 3-glucosyltransferase; RT: anthocyanin rhamnosyl transferase.

Fig. 2 - 2-DE profile of proteins differentially accumulated in corolla limbs of Petunia hybrida

800 AN1 (R27) and an1 (W225) lines at 1 day after anthesis. The figure reports one of the

801 electrophoretic maps of the R27 corolla limbs. Total proteins (400 $\mu \mathrm{g})$ were analyzed by IEF at $\mathrm{pH} 4-7$, followed by $10 \%$ SDS-PAGE and visualized by cCBB staining. Acronyms refer to Table 1. Protein with higher accumulation level in R27 red flowers are reported in red, those

804 more abundant in W225 white flowers are reported in black. Standard molecular mass range in $805 \mathrm{kDa}(\mathrm{Mr})$ and $\mathrm{p} I$ range are reported on the left and above, respectively.

806

807

Fig. 3 - Functional distribution of the characterized proteins in corolla limbs of Petunia hybrida 808 flowers. The proteins differentially accumulated in corolla limbs of petunia AN1 (R27) and an1 809 (W225) lines are classified in nine distinct functional classes, according to function assignment 810 in literature and GeneBank. Functional distribution indicates the percentage of each metabolic 811 class as compared to the total number of identified proteins (56, see Table 1 and Fig. 2). 


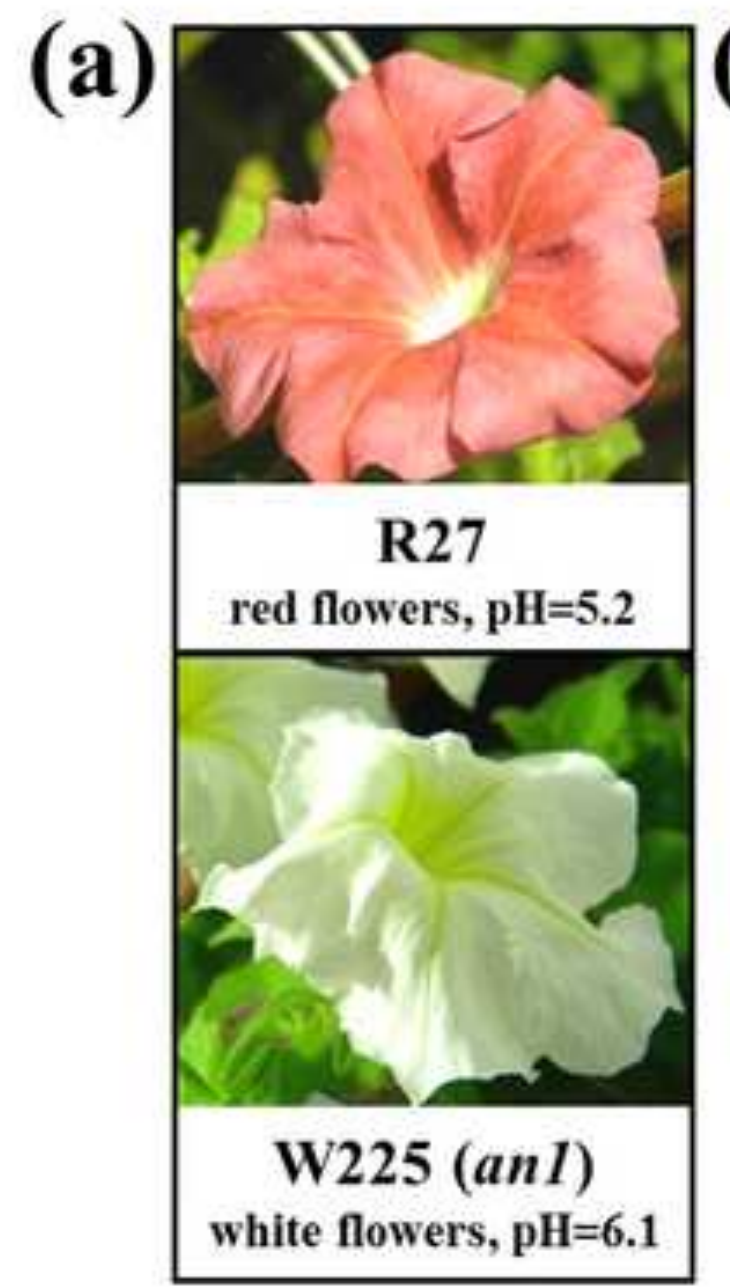

\section{(b)}

Malonyl-CoA + p-Coumaroyl-CoA

$\downarrow$ CHS

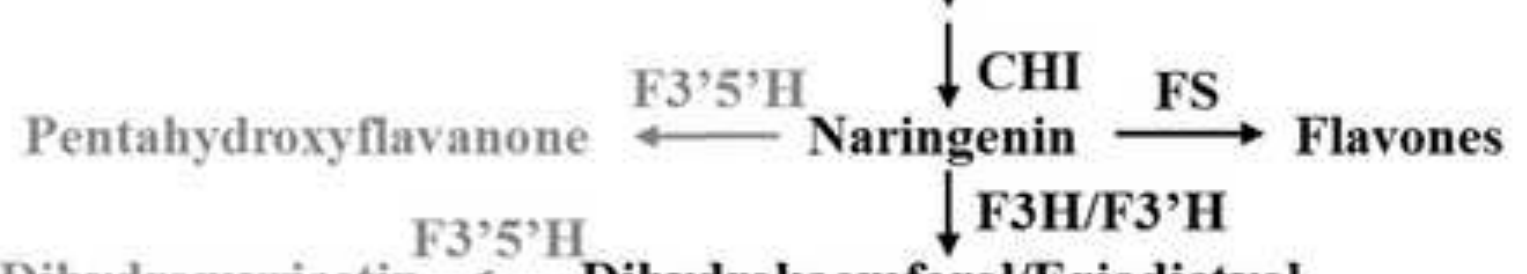

Dihydromyricetin $\stackrel{ }{\mathrm{F}}{ }^{\prime}{ }^{\prime}$ Dihydrokaemferol/Eriodictyol

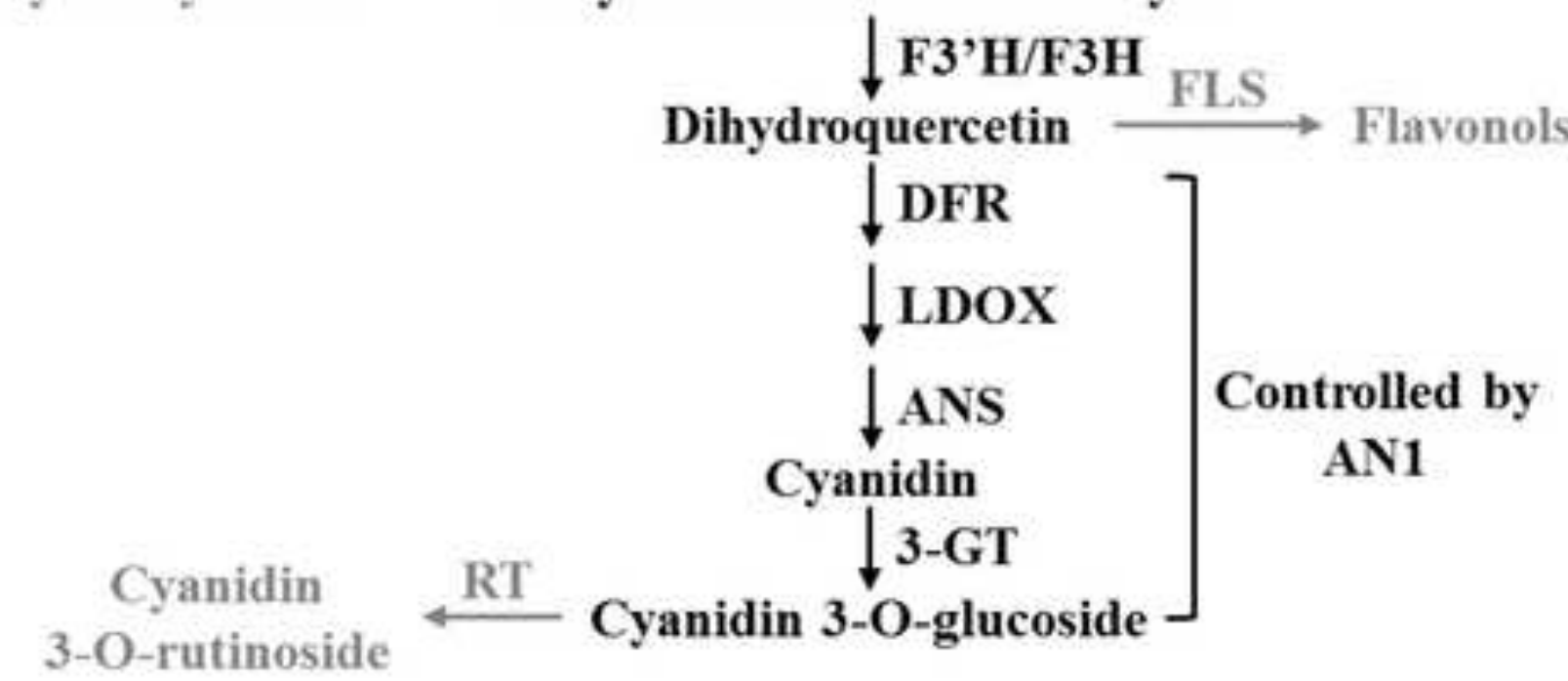

AN1 
Click here to download high resolution image

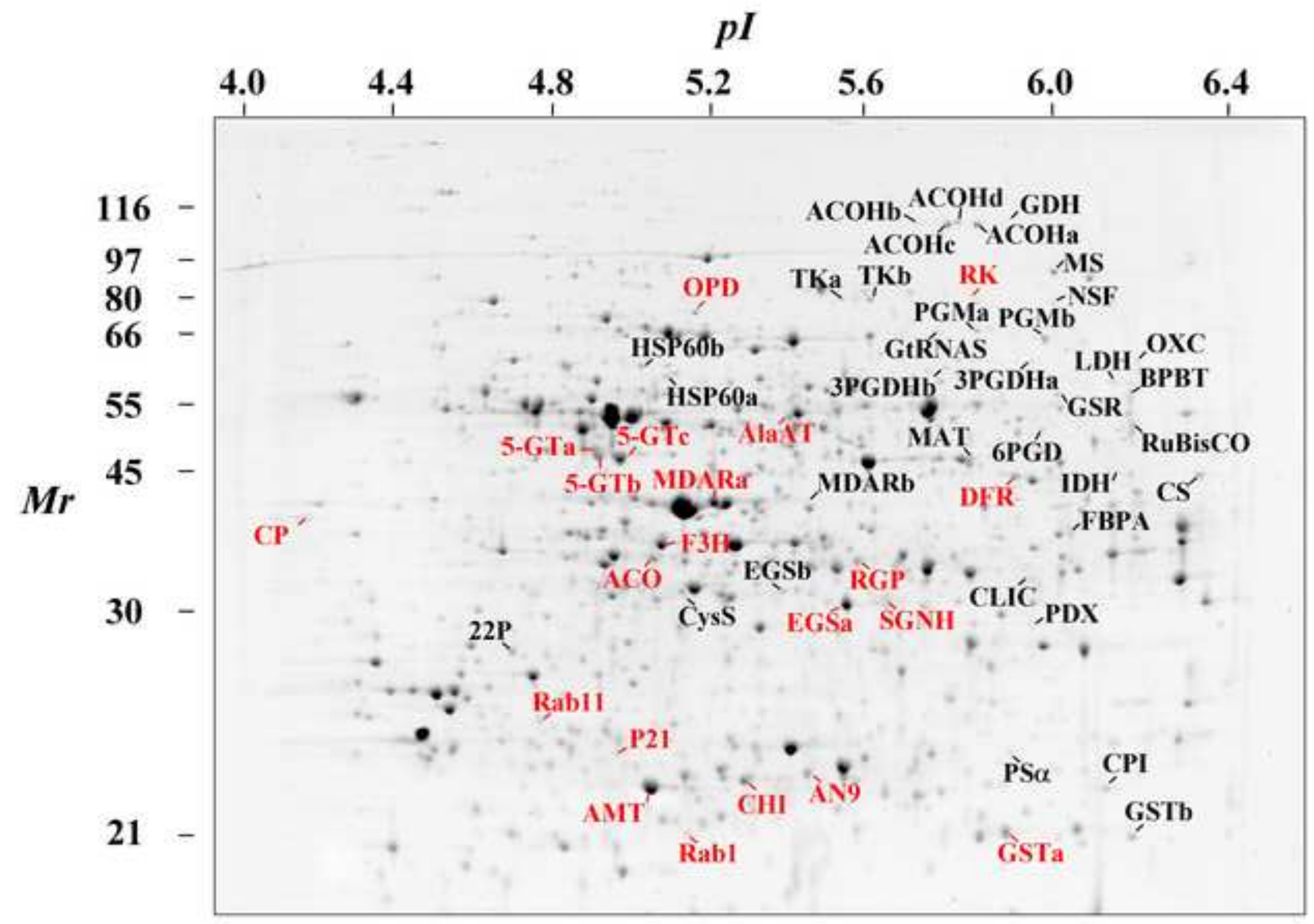


$\square$ Anthocyanin metabolism

$\square$ Carbon metabolism

$\square$ Mitochondrial metabolism

$\square$ Amino acid metabolism

口Endomembrane system

$\square$ Volatiles biosynthesis

$\square$ Protein turnover

$\square$ Redox status

$\square$ Hormone biosynthesis

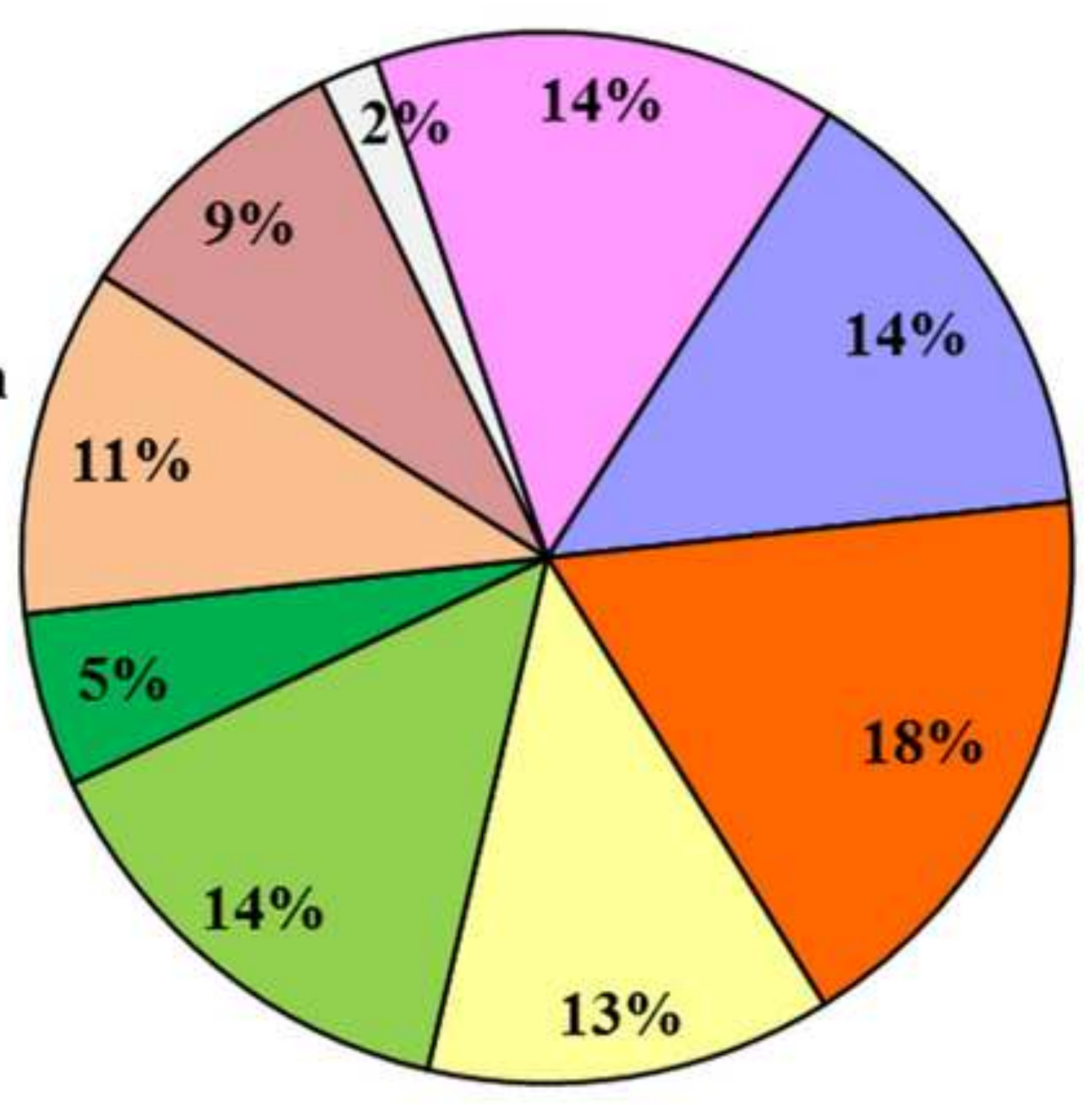



Supplementary material
Click here to download Supplementary material: Supplementary data Prinsi et al revised.pc Supplementary material
Click here to download Supplementary material: Supplementary data Prinsi et al revised.pdf

\begin{abstract}
che here to download Supplementary material: Supplementary data Prinsi et al revised.pdf
\end{abstract}

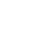

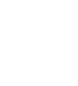

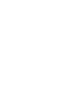
(n)

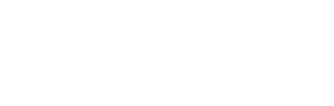
$x^{2}$

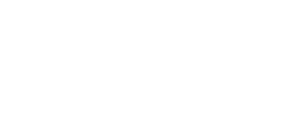
.

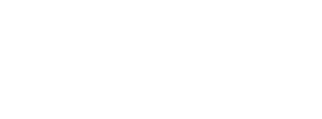
(1) (1) (1) (1) (1) (1) (1) (1) (1) (1) (1) (1) (1)

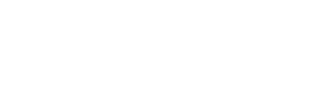


${ }^{*}$ Conflict of Interest
Click here to downloa

Click here to download Conflict of Interest: Conflict of interest Prinsi et al revised.pdf

\begin{abstract}
Click here to download
\end{abstract}

